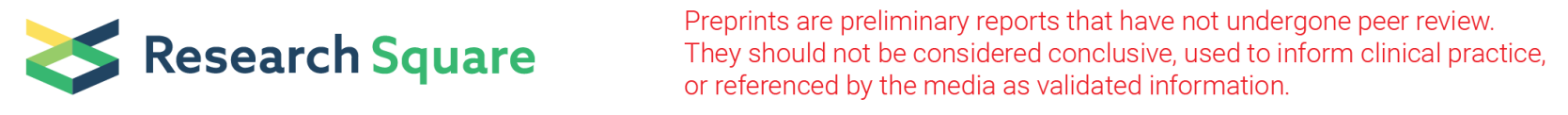

\title{
Prevalence of Primary Headache Disorder Among Primary and middle School students in Kuwait.
}

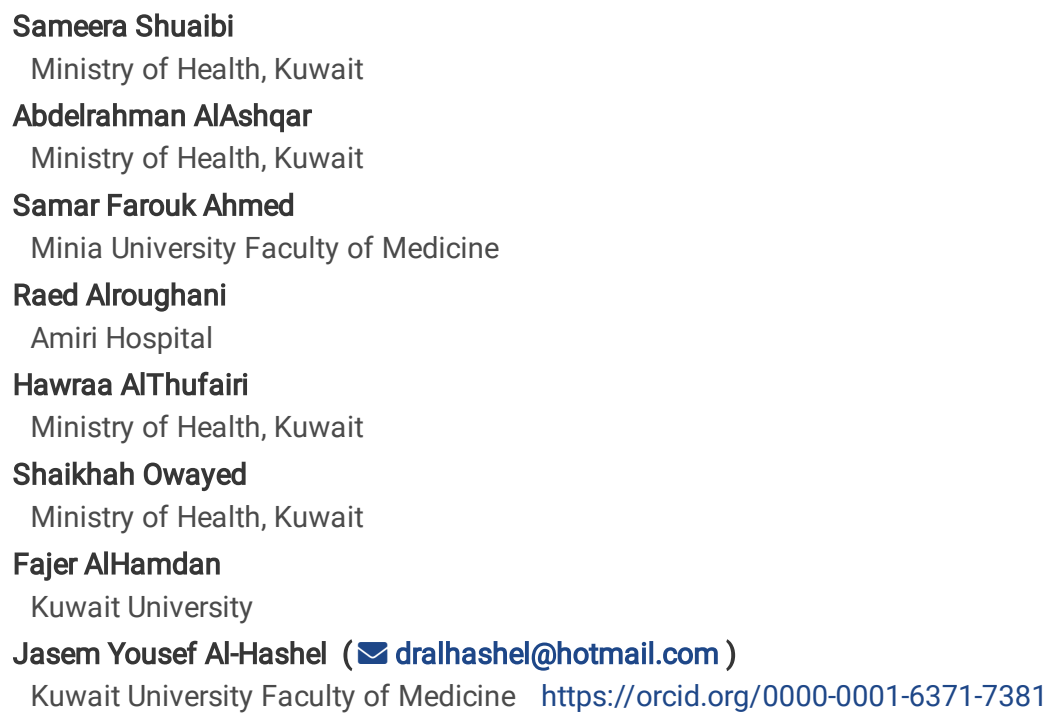

Sameera Shuaibi

Ministry of Health, Kuwait

Abdelrahman AlAshqar

Ministry of Health, Kuwait

Samar Farouk Ahmed

Minia University Faculty of Medicine

Raed Alroughani

Amiri Hospital

Hawraa AlThufairi

Ministry of Health, Kuwait

Shaikhah Owayed

Ministry of Health, Kuwait

Fajer AlHamdan

Kuwait University

Jasem Yousef Al-Hashel ( $\nabla$ dralhashel@hotmail.com )

Kuwait University Faculty of Medicine https://orcid.org/0000-0001-6371-7381

\section{Research article}

Keywords: Primary, Headache, Prevalence, School students

Posted Date: April 7th, 2020

DOI: https://doi.org/10.21203/rs.3.rs-20472/v1

License: (c) (i) This work is licensed under a Creative Commons Attribution 4.0 International License. Read Full License

Version of Record: A version of this preprint was published at Journal of the Neurological Sciences on October 1st, 2019. See the published version at https://doi.org/10.1016/j.jns.2019.10.1620. 


\section{Abstract}

Background Primary headaches are remarkably prevalent worldwide and increasingly reported among children. However, the exact trend in this age group, particularly in the gulf region, remains scarce. Aims and Objectives To examine the prevalence of primary headache disorders among primary and middle school students in Kuwait.

Methods We conducted a cross-sectional study that included Kuwaiti primary and middle school children and adolescents of both genders in randomly selected schools located in two governorates in Kuwait in 2018/2019 academic year. Prevalence and attributable burden of headache, definite and probable migraine,definite and probable tension-type headache, chronic headache $\geq 15$ days/month and probable medication over use headache were assessed using the Headache-Attributed Restriction, Disability, Social Handicap and Impaired Participation (HARDSHIP) questionnaire for children and adolescents.

Results Of 1485 questionnaires that were distributed, 1091 students completed the questionnaire with a respondent rate of $73.4 \%$. The study population consisted of 422 boys (38.68\%) versus 669 girls (61.32\%) students with a mean age of $11.5 \pm 2.11$ years. The lifetime prevalence of any headache was $85.2 \%$, whereas the one-year prevalence of primary headache disorders was $42.71 \%$ The mean age of students with primary headaches was $11.98 \pm 2.03$ years in both genders. When stratified according to diagnostic criteria, migraine headaches were the most frequently reported (20.81\%) followed by tension type headaches (18.7\%), chronic headaches (2.75\%), and probable medication-overuse headaches (0.46\%.). Primary headaches were more frequently reported in middle school compared to primary school $(50.37 \%$ versus $30.48 \%$; $P<0.02)$. It was significantly higher among girls compared to boys in middle-schoolers ( $66.46 \%$ versus $38.49 \%$; $p<0.001)$, however no significant difference in gender among primary school students(33.12\% versus $22.33 \%$; $p<0.118)$.

Conclusion Primary headaches are remarkably common in Kuwaiti school students with migraine headache being the most frequently reported type. Age and female gender play a role in the development of primary headaches. The results attract attention of health services for such group and the need for further epidemiological researches.

\section{Introduction}

Headache, or cephalgia, is one of the most common disorders in childhood, with an estimated $75 \%$ of children reporting significant headache by the age of 15 years [1]. It is defined as head pain that occurs anywhere in the head or neck areas [2]. Headaches amongst children and adolescents are categorized into primary and secondary headaches; the most common primary headaches constitute migraine headaches, tension-type headaches and cluster headaches. These are paralleled in the same manner amongst adults. In children, headaches are commoner among the older segment than the younger ones being considered rare prior to the age of 4 . In particular, the peak age for headaches in children is 13 [3-4]. Headaches are accompanied by a wide range of burdens both to the patient's own quality of life as well as the economy [5-7]. In specific, it was found that school attendance was affected amongst children with headaches [8]. Additionally, the same children are more prone to develop psychiatric disorders such as depression and anxiety as well as other somatic symptoms such as abdominal pain [9-11]. Moreover, approximately $50 \%$ of the global population is affected by headaches mounting up to $£ 600$ million per annum in the UK and between 5.6-17.2 billion in the US [12]. Prevalence studies concerning headaches are scarce worldwide especially concerning the pediatric and adolescent age groups; in specific, the Arab world including Kuwait are lacking in this entity. Thus, a research of this kind is conducted to shed light onto the prevalence of headaches in children and adolescents. Data of this sort is essential to illustrate the magnitude that headaches possess in Kuwait. Once the burden is recognized, efforts can be implemented to improve the patients' quality of life in the future that can have positive governmental impacts in terms of the economy.

\section{Methods}

We conducted a cross-sectional study with a school-based sample whereby a questionnaire was distributed to primary and middle schoolchildren aged 7-16 years in governmental schools in Kuwait. Equal boys and girls schools were randomly selected from two major governorates in Kuwait; AlFarwaniyah, the most densely populated and farther away from the center of the State of Kuwait, and Hawally, which is more urbanized and central in location. These two governorates were chosen to cover the geographic diversity of Kuwait.

\section{Population of Interest}

Study population included Kuwaitis schoolchildren aged 7-16 years.

\section{Sample Size}

According to the information from Kuwait Ministry of education in academic year 2018/2019, the number of Kuwait students in primary and middle schools is 127653 . Of those, 71448 (55.97\%) are girls and 56205 (44.03\%) are boys. Hence, the sample size was calculated and determined to be 950 using a special formula based on reported prevalence of headache from previous national and international epidemiological studies, which is around $54.4 \%$ and of migraine, $9.1 \%$ [13-14]. Then, the sample was increased by $20 \%$ to overcome the problem of non-response and missing data. Five hundred complete questionnaires were obtained from Al-Farwaniyah governorate and 591 complete questionnaires were obtained from Hawally governorate.

Page 2/10 


\section{Survey and Sampling}

Representative random sample of school classes was selected, stratified by grade (3rd, 5th, 7th, 9th ), and school type (school for boys and schools for girls). So, the final selection of schools and school classes that were idensified for this study covered age spectrum from childhood through adolescence and reflected Kuwaiti students of schools appropiately. All children and adolescents within these selected classes were included, except for those who refused to participate, were non-Kuwaiti nationals, has history of medical or neurological disease or were absent on the day of the survey.

Of 1485 questionnaires that were distributed, 1091 students completed the questionnaire with a respondent rate of $73.4 \%$. Figure 1 displays the flow chart.

\section{Study Tools}

The survey used Lifting the Burden, Headache-Attributed Restriction, Disability, Social Handicap and Impaired Participation (HARDSHIP) questionnaire that was translated into Arabic [15]. The Child HARDSHIP for children aged 6-11 years and Adolescent HARDSHIP questionnaire for adolescents aged 12- 17 years were used in this study. The HARDSHIP questionnaire has already demonstrated validity and acceptability in multiple languages and cultures including the Arabic Language. This questionnaire questions including sociodemographic, screening and diagnostic questions and enquiries into burden in various domains and quality of life. The last part of the questionnaire included questions on the use of healthcare system in the past, medication use, and Headache-Attributed Lost Time Index questionnaire. Burden questions referred to the numbers of days missed from school, leaving school early or with impaired everyday activities due to headache, within the previous four weeks. Data were obtained from the children and adolescents themselves after explanation of the questions by physician of the study team. Questionnaire distribution and data collection were organized and conducted by physician supervisors during a school class as a paper-pencil version. To collect study data, well trained physicians conducted face to face interviews using Child and Adolescent HARDSHIP questionnaires

\section{Diagnosis of headache}

Diagnoses were performed by HARDSHIP algorithm) applying ICHD-3 criteria is [16-17]. Following the section on personal details and demographic data, a question was introduced: "In the last year, have you had a headache that was not part of another illness?" Participants who responded with "no" were classified as headache-free; those who responded with "yes" were asked whether their headache episodes were of one or more types. If the child reported more than one type of headache, subsequent questions targeted the most bothersome headache type. For diagnose of headache type, we asked questions about headache frequency and duration, headache characteristics, associated symptoms and use of acute medication. We separated those reporting headache days for 15 or more, and diagnosed propable medication over use headache (pMOH) when acute medication was used on 10 or more days/ month. Participants reporting headache on less than 15 days/month we applied diagnostic criteria, in order, for definite migraine, definite tension type headache (TTH), probable migraine and probable TTH. Participants with headache who fell into none of these categories were categorized as "unclassifiable headache".

\section{Quality Assurance and Validity}

The team leader reliably stored all completed questionnaires at the end of each day. Errors were corrected by discussing them with the interviewer and a revisit was arranged if discrepancies could not be corrected. The team leader monitored and assisted researchers on a regular basis to resolve any problems and to review the completed questionnaires.

\section{Duration of the Project}

The fieldwork was carried out over a period of 3 months from 1/10/2018 till 1/1/2019.

\section{Ethics}

Ministry of health and ministry of Education in Kuwait approved the study. Participants was given a simple explanation about the aim of the study being considered an ethical issue. Written informed consent was obtained from all participants and their parents before the questionnaire was distributed. The participants were granted the right to decline participation at any time during data collection. All data were protected in accordance with the ethical guidelines of the Council for International Organizations of Medical Sciences and the principles in the Declaration of Helsinki [18-19].

\section{Data Analysis}

We used IBM SPSS Statistics 20.0. Completed questionnaire data and double check of all data was made, with inconsistencies reconciled by reference to the original documents. Error rate of $1.9 \%$ was identified. One year prevalence for primary headache disorders as percentages with $95 \%$ Cls. Adjusted prevalence for gender and school stage according to the participation of the Kuwaiti students was reported. Duration of headache was recorded as continuous data in hours. Headache frequency was recorded in days over the preceding 3 months, and typical headache intensity on a verbal rating scale ("not bad," "quite bad," and "very bad"). We used proportions, 95\% Cls, means, and SDs to summarize the distributions of variables and chi-square, for significance of differences. $P<0.05$ was considered as statistically significant.

\section{Results}


Table 1 demonstrates the sociodemographic characteristics of the study population. A total of 1091 students participated in the study, of which 420 were primary school students and the remainder were middle school students. The study population consisted of 422 male (38.68\%) and 669 female (61.32\%) students with the majority being middle schoolers in both genders. The mean age of the participants was $11.5+/-2.11$ years. Collectively, $85.2 \%$ of students reported having any headache at least once in their lifetime, whereas $78.09 \%$ students had at least one episode in the past year with most episodes being reported by middle schoolers. The 1-year prevalence of primary headache disorders, however, was found to be $42.71 \%$ (Table 1 ). When stratified according to diagnostic criteria, migraine headaches were the most commonly reported (20.81\%) followed by tension type headaches (18.7\%), chronic headaches $(2.75 \%)$, and probable medication-overuse headaches $(0.46 \%$.).

Table 2 demonstrate the sociodemographic characteristics of students with headache. The mean age of students with primary headaches was 11.98 $+/-2.03$ years in both genders. When stratified according to gender, $31.12 \%$ of boys experienced primary headaches as compared to $68.88 \%$ of girls. Primary headaches were more frequently reported among boys and girls middle-schoolers. Within the past month, students reported a mean of 6.24 +-/ 5.18 days of headaches with a mean duration of 9.12 +/- 2.51 hours per attack and a mean of $3.26+/-4.2$ days of analgesia use. As regards severity, the majority of students (59.44\%) labeled their headaches as 'quite bad', whereas $17.38 \%$ of students experienced 'very bad' headaches. Headache reporters had to lose a mean of $0.99+/-2.015$ days off school due to headaches and had to leave school early on a mean of $0.77+/-$ 1.69 days.

Table 3 demonstrated the one-year prevalence of primary headache disorders stratified by school stage and gender. Primary headaches were more frequently reported in middle school compared to primary school $(50.37 \%$ versus $30.48 \%$; $<0.01)$. Of male students, $22.33 \%$ of primary schoolers reported primary headaches as compared to $38.49 \%$ of middle schoolers (Table 3 ). This was similarly observed among females where middle schoolers with primary headaches (66.46\%) within the past year were double the number of female primary schoolers (33.12\%). The 1 -year prevalence of primary headaches was significantly higher among females compared to males in middle-schoolers $(66.46 \%$ versus $38.49 \%$; $p<0.001)$, however no significant difference in gender among primary school students(33.12\% versus $22.33 \%$; $<<0.118)$.

Among primary schoolers, migraine headaches (28.1\%) were the most reported in both genders followed by tension type headaches (24.9\%) (Table 4). Female primary schoolers reported all types of primary headaches more frequently than their male counterparts but no significant difference among gender.

Similarly, migraine headaches were the most frequently reported type amongst female (29.26\%) and male (18.18\%) middle schoolers (Table 5). This was followed by tension type headache, chronic headaches, and probable medication-overuse headaches in that order. Female Gender of middleschoolers was significantly associated with a diagnosis of migraine headache $(P<0.001)$ and tension type headache $(P<0.0001)$.

Table 1

Demographic data and Prevalence of Headache among School Students.

\begin{tabular}{|c|c|c|c|}
\hline Variables & $\begin{array}{l}\text { Total School students } \\
\mathrm{N}=1091 \\
\mathrm{M} \pm \mathrm{SD} / \mathrm{No}(\%)[\mathrm{Cl} 95 \%]\end{array}$ & $\begin{array}{l}\text { Primary School Students } \\
\mathrm{N}=420 \\
\mathrm{M} \pm \mathrm{SD} / \mathrm{No}(\%)[\mathrm{Cl} 95 \%]\end{array}$ & $\begin{array}{l}\text { Middle School Students } \\
\mathrm{N}=671 \\
\mathrm{M} \pm \mathrm{SD} / \mathrm{No}(\%)[\mathrm{Cl} 95 \%]\end{array}$ \\
\hline $\begin{array}{l}\text { Gender: } \\
\text { - Male } \\
\text { - Female }\end{array}$ & $\begin{array}{l}422(38.68 \%)[35.83-41.61] \\
669(61.32)[58.39-64.17]\end{array}$ & $\begin{array}{l}103(24.52 \%)[20.65-28.86] \\
317(75.48 \%)[71.14-79.35]\end{array}$ & $\begin{array}{l}317(47.24 \%)[43.49-51.03] \\
352(52.46 \%)[48.68-56.21]\end{array}$ \\
\hline $\begin{array}{l}\text { Mean Age in years } \\
\text { Range }\end{array}$ & $\begin{array}{l}11.50 \pm 2.11 \\
7-17\end{array}$ & $\begin{array}{l}9.20 \pm 0.10 \\
7-12\end{array}$ & $\begin{array}{l}12.94 \pm 1.13 \\
10-17\end{array}$ \\
\hline Life time prevalence of Any Headache & 929 (85.15\%) [82.91-87.14] & $312(74.29 \%)[69.89-78.24]$ & 617 (91.95\%) [89.63-93.79] \\
\hline One Year Prevalence of Any Headache & $852(78.09 \%)$ [75.54-80.45] & $271(64.52 \%)$ [59.83-68.95] & $581(86.59 \%)$ [83.79-88.97] \\
\hline $\begin{array}{l}\text { One Year Prevalence of Primary Headache disorder } \\
\text { - Migraine } \\
\text { - TTH } \\
\cdot \text { CH } \\
\text { - MOH }\end{array}$ & $\begin{array}{l}466(42.71 \%)[39.81-45.67] \\
227(20.81 \%)[18.50-23.32] \\
204(18.70 \%)[16.49-21.12] \\
30(2.75 \%)[1.92-3.91] \\
5(0.46 \%)[0.16-1.1]\end{array}$ & $\begin{array}{l}128(30.48 \%)[26.26-35.04] \\
65(15.48 \%)[12.32-19.26] \\
55(13.10 \%)[10.18-16.68] \\
7(1.67 \%)[0.74-3.47] \\
1(0.24 \%)[0.01-1.48]\end{array}$ & 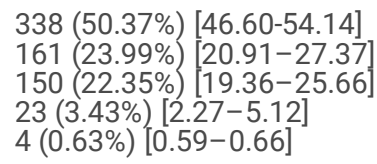 \\
\hline
\end{tabular}


Characters of Primary Headache among school children with Primary Headache Disorders (No = 466)

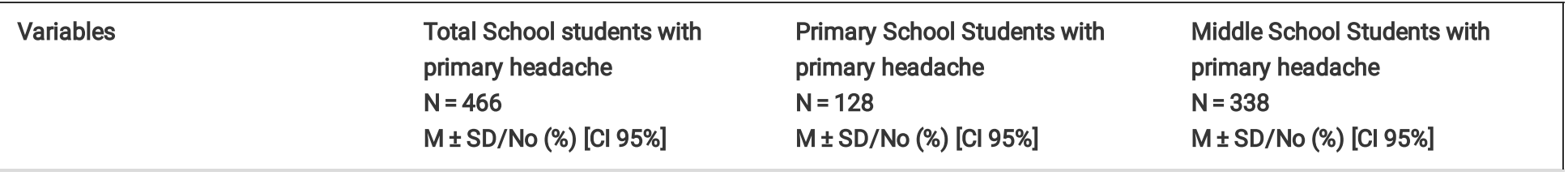

\begin{tabular}{|c|c|c|c|}
\hline $\begin{array}{l}\text { Gender: } \\
\text { - Male } \\
\text { - Female }\end{array}$ & $\begin{array}{l}145(31.12 \%)[27.08-35.46] \\
321(68.88 \%)[64.54-72.92]\end{array}$ & $\begin{array}{l}23(17.97 \%)[12.22-25.59] \\
105(82.03 \%)[74.41-87.78]\end{array}$ & $\begin{array}{l}216(63.91 \%)[58.65-68.85] \\
122(36.09 \%)[31.15-41.35]\end{array}$ \\
\hline $\begin{array}{l}\text { Mean Age in years } \\
\text { Range }\end{array}$ & $\begin{array}{l}11.98 \pm 2.03 \\
7-17\end{array}$ & $\begin{array}{l}9.22 \pm 0.99 \\
7-12\end{array}$ & $\begin{array}{l}13.03 \pm 1.16 \\
11-17\end{array}$ \\
\hline $\begin{array}{l}\text { Number of headache days in the } \\
\text { last four weeks }\end{array}$ & $6.24 \pm 5.18$ & $5.28 \pm 4.82$ & $6.58 \pm 5.27$ \\
\hline $\begin{array}{l}\text { Duration of attacks in hours in the } \\
\text { last four weeks }\end{array}$ & $9.12 \pm 2.51$ & $8.82 \pm 2.16$ & $9.32 \pm 3.11$ \\
\hline $\begin{array}{l}\text { Number of analgesic days in the } \\
\text { last four weeks }\end{array}$ & $3.26 \pm 4.20$ & $3.03 \pm 3.45$ & $3.35 \pm 4.45$ \\
\hline $\begin{array}{l}\text { Severity of headache } \\
\text { - Not bad } \\
\text { - Quite bad } \\
\text { - Very bad }\end{array}$ & $\begin{array}{l}108(23.18 \%)[19.57-27.22] \\
277(59.44 \%)[54.92-63.81] \\
81(17.38 \%)[14.20-21.10]\end{array}$ & $\begin{array}{l}27(21.09 \%)[14.87-29.00] \\
85(86.94 \%)[84.68-88.91] \\
16(12.50 \%)[7.74-19.44]\end{array}$ & $\begin{array}{l}81(23.96 \%)[19.71-28.80] \\
192(65.80 \%)[51.48-61.98] \\
65(19.23 \%)[15.37-23.78]\end{array}$ \\
\hline
\end{tabular}

Table 3

One-year prevalence of Primary headache disorders stratified by school stage and gender

\begin{tabular}{|c|c|c|c|c|c|c|c|c|c|c|}
\hline $\begin{array}{l}\text { Primary } \\
\text { headache } \\
\text { disorder }\end{array}$ & Total & & & Male & & & Female & & & $\mathbf{P}$ \\
\hline $\begin{array}{l}\text { School } \\
\text { class }\end{array}$ & $\begin{array}{l}\text { Participant } \\
\text { Students }\end{array}$ & $\begin{array}{l}\text { Headache } \\
\text { cases }\end{array}$ & $\begin{array}{l}\text { Prevalence } \\
\%(\mathrm{Cl} 95 \%)\end{array}$ & $\begin{array}{l}\text { Participant } \\
\text { Students }\end{array}$ & $\begin{array}{l}\text { Headache } \\
\text { cases }\end{array}$ & $\begin{array}{l}\text { Prevalence } \\
\%(\mathrm{Cl} 95 \%)\end{array}$ & $\begin{array}{l}\text { Participant } \\
\text { Students }\end{array}$ & $\begin{array}{l}\text { Headache } \\
\text { cases }\end{array}$ & $\begin{array}{l}\text { Prevalence } \\
\%(\mathrm{Cl} 95 \%)\end{array}$ & \\
\hline $\begin{array}{l}\text { Primary } \\
\text { School }\end{array}$ & 420 & 128 & $\begin{array}{l}30.48 \% \\
(26.26- \\
35.04)\end{array}$ & 103 & 23 & $\begin{array}{l}22.33 \% \\
(15.31- \\
31.34)\end{array}$ & 317 & 105 & $\begin{array}{l}33.12 \\
(28.17- \\
38.48)\end{array}$ & 0.118 \\
\hline $\begin{array}{l}\text { Middle } \\
\text { School }\end{array}$ & 671 & 338 & $\begin{array}{l}50.37 \% \\
(46.60 . \\
-54.14)\end{array}$ & 317 & 122 & $\begin{array}{l}38.49 \% \\
(33.30- \\
43.95)\end{array}$ & 352 & 216 & $\begin{array}{l}66.46 \% \\
(61.16-71 . \\
38)\end{array}$ & 0.001 * \\
\hline Total & 1091 & 466 & $\begin{array}{l}42.71 \% \\
(39.81- \\
45.67)\end{array}$ & 422 & 145 & $\begin{array}{l}34.36 \% \\
(29.99- \\
39.02)\end{array}$ & 669 & 321 & $\begin{array}{l}47.98 \% \\
(44.22- \\
51.77)\end{array}$ & $0.001^{*}$ \\
\hline
\end{tabular}


Table 4

One-year prevalence of Types of Primary headache disorders stratified by gender in primary school students $(\mathrm{N}=420)$.

\begin{tabular}{|c|c|c|c|}
\hline \multirow[t]{2}{*}{ Types of Primary headache disorder } & Male $(N=103)$ & Female $(\mathrm{N}=317)$ & $\mathbf{P}$ \\
\hline & $\mathrm{N}(\%)$ [Cl 95\%] & $\mathrm{N}(\%)$ [Cl 95\%] & \\
\hline Migraine & $\begin{array}{l}11(10.7 \%) \\
{[15.31-31.34]}\end{array}$ & $\begin{array}{l}44(17.4 \%) \\
{[28.17-38.48]}\end{array}$ & 0.120 \\
\hline TTH & $\begin{array}{l}12(11.7 \%) \\
{[33.30-43.95]}\end{array}$ & $\begin{array}{l}42(13.2 \%) \\
(61.16-71.38)\end{array}$ & 0.674 \\
\hline $\mathrm{CH}$ & 0 & $\begin{array}{l}7(2.2 \%) \\
{[44.22-51.77]}\end{array}$ & 0.128 \\
\hline pMOH & 0 & $1(0.3 \%)$ & 0.568 \\
\hline
\end{tabular}

TTH: tension type headache; $\mathrm{CH}$ : chronic headache; $\mathrm{pMOH}$ : probable medication-overuse headache; M: mean, SD: standard deviation; $\mathrm{Cl}$ 95\%: confidence interval 95\%

Table 5

One-year prevalence of Types of Primary headache disorders stratified by gender in Middle school students $(N=671)$.

\begin{tabular}{|c|c|c|c|}
\hline Types of Primary headache disorder & $\begin{array}{l}\text { Male (N = 319) } \\
\mathrm{N}(\%)[\mathrm{Cl} 95 \%]\end{array}$ & $\begin{array}{l}\text { Female }(\mathrm{N}=352) \\
\mathrm{N}(\%)[\mathrm{Cl} 95 \%]\end{array}$ & $\mathbf{P}$ \\
\hline Migraine & $\begin{array}{l}58(18.18 \%) \\
{[14.32-22.80]}\end{array}$ & $\begin{array}{l}103(29.26 \%) \\
{[24.75-34.22]}\end{array}$ & $0.001^{*}$ \\
\hline TTH & $\begin{array}{l}52(16.30 \%) \\
{[12.63-20.77]}\end{array}$ & $\begin{array}{l}98(27.84 \%) \\
{[23.41-32.75]}\end{array}$ & $0.0001 *$ \\
\hline $\mathrm{CH}$ & $\begin{array}{l}10(3.13 \%) \\
{[1.64-5.75]}\end{array}$ & $\begin{array}{l}13(3.72 \%) \\
{[3.23-4.23]}\end{array}$ & 0.691 \\
\hline pMOH & $\begin{array}{l}2(0.63 \%) \\
{[0.02-2.41]}\end{array}$ & $\begin{array}{l}2(0.57 \%) \\
{[0.02-2.19]}\end{array}$ & 0.921 \\
\hline
\end{tabular}

\section{Discussion}

Our study included only Kuwaiti students who are resident in Kuwait over last year before the survey. Our results demonstrated that a substantial proportion of Kuwaiti primary and middle school children suffered from primary headache disorders. We reported a 1-year prevalence of primary headaches of $42.71 \%$ among our study population. This represents a remarkable difference from the results of our previous epidemiological study that demonstrated a 1-year prevalence of $19.4 \%$ of primary headache disorders in children and adolescents approached in the community [13]. This discrepancy can be contributed to the two different approaches in each study. Children approached in their homes may be influenced by the presence of their parents, who in fact may be the major source of the data, potentially underreporting actual figures. On the other hand, children approached in schools self-report their complaints without any parental influence. Nevertheless, our results are fairly comparable to international studies similarly targeting school children. In Turkey, 46.2\% of schoolchildren aged 6-10 years were found to have headaches over a 1-year period [20]. In another study conducted in the South Korea [21], 29.1\% of schoolchildren of both genders reported having a headache over the past year. These consistent results emphasize the significant magnitude of the young population affected by primary headaches, a diagnosis that was once primarily seen to have an adult predilection. Other studies, on the contrary, reported substantially higher or lower proportions of children with headaches. For example, $75.7 \%$ of Austrian schoolchildren and adolescents aged 10-18 years were found to have headaches over a 1-year period [22], while 88\% of Dutch elementary and secondary schoolchildren of both genders reported having a headache at least once over the previous year [23]. Many factors could contribute to variations in reported results, including biological, environmental, cultural, geographical and those pertaining to methodological differences and diagnostic criteria used in each study.

Our results found that age played an important role in the development of headaches. It was reported more frequently amongst middle schoolers compared to primary schoolers. This applies to both genders. This was also observed in our previous epidemiological study [13, 24]. In further support of our findings, epidemiologic cross-sectional [24-26] and longitudinal [27] studies show that the prevalence of headaches increases with age. Our findings were in line with an American study that yielded a prevalence of $12.84 \%$ amongst 6 to 12 year old versus $21.71 \%$ that of 12 to 16 year olds [27]. This was also paralleled in a Canadian study whereby $26.3 \%$ of 12 - to 13 -year-olds and $31.2 \%$ of the 14 - to 15 -year-olds experienced headaches [28]. Gaßmann [29] reported that $3.6 \%$ of 8 -year-olds and $10.7 \%$ of 15 -year-olds had at least one headache weekly. Similar results were mirrored in Germany, Southern England, as well as in Italy [27, 30, 31]. 
We found that most children suffering from migraine headache (20.81\%) followed by tension type (18.7\%), chronic (2.75\%), and probable medicationoveruse $(0.46 \%$.) headaches. This was similarly documented by other studies where migraine headache was followed in frequency by other headache types [18, 32, 33]. In contrast, Rho et al reported tension type headache as the most frequent type among Korean schoolchildren followed by migraine headache [21]. Our results reported a significantly higher 1-year prevalence of primary headaches among females compared to males. This observation was noted in the overall study population (47.98\%vs. $34.36 \% ; P<0.001)$ and among middle schoolers (66.46\% vs. $38.49 \% ; P<0.001)$ but rendered nonsignificant among primary schoolers. This was reiterated by Zwart et al [34], Mehta [32], and our community-based epidemiological study [13], where we found a significantly higher prevalence of headaches among girls.

When stratified according to diagnostic criteria, migraine $(29.26 \%$ vs. $18.18 \% ; P<0.001)$ and tension type $(27.84 \%$ vs. $16.3 \% ; P<0.0001)$ headaches were more significantly reported among female middle schoolers compared to males. However, differences were not statistically significant among primary schoolers and for other types of headaches among middle schoolers. These findings go in line with other epidemiological studies, including our own [15]. Laurell et al detected a higher rate of migraine and tension type headaches among females [25], a finding that was similarly reported by Lyngberg et al, where the male: female ratio for migraine and tension type headaches was 1:6 and 1:3, respectively [35]. These findings point to an increased risk of females to develop primary headaches, particularly migraine and tension type headaches, compared to their male counterparts. It has been already established in the literature that women are at increased risk of developing migraine headaches and are 3.25 more likely to suffer from migraine than men [36]. From a pathophysiological perspective, the female brain manifests a sex-specific activity that can be detected via functional neuroimaging in terms of cortical regions involved in pain modulation and affective processing, such as the insula and precuneus, display enhanced activation in women [37].

\section{Strengths and Limitations of the Study}

Our study had several strengths. It is the first of its kind in Kuwait and the Gulf region providing valuable data on the prevalence of primary headache disorders among children and adolescents and their association with gender. Our study represents a great contribution to the regional and global headache epidemiological dataset by closing gaps in the attributable burden of primary headaches in the region. It generated a large randomized stratified sample representative of the entire country. Information obtained from this study may potentially help in predicting the future trends of primary headaches as well as deciding on the optimal management of this disorder in the pediatric population via strategies similar or different from those used in adults.

Our study has limitations inherent to its retrospective design, including recall bias introduced by answering the questionnaire, and the reliance on self reports of clinical parameters of headaches. Being a cross-sectional study, associations between headache and age and gender could not be interpreted in a causal manner.

\section{Conclusions}

Primary headache disorders are remarkably common in children and adolescents of Kuwait and occur in frequencies comparable to elsewhere worldwide. Migraine is the most prevalent type in both genders. Female adolescents have a significantly higher risk of developing migraine and tension type headaches compared to their male counterparts, a finding that was not observed among primary schoolers or with other types of headaches. This suggests an increased propenicity of the adolescent female to develop primary headaches possibly mediated by sex-specific phenomena that affect select regions in the female brain.

\section{Abbreviations}

Chronic headache

$\mathrm{CH}$

Headache-Attributed Restriction, Disability, Social Handicap and Impaired Participation

HARDSHIP

International Classification of Headache Disorders III

ICHD-III

Probable Medication over use headache

$\mathrm{pMOH}$

Tension Type Headache

TTH

\section{Declarations}

\section{Ethics approval and consent to participate}

Not applicable

\section{Consent for publication}


Not applicable.

\section{Competing interests}

No competing interests.

\section{Funding}

This study did not receive any grant from any funding agency in the public, commercial, or not-for-profit sectors.

\section{Authors' contributions}

JA-H designed the study and reviewed the manuscript. SF A designed the study, performed statistical analysis, criticized and reviewed the manuscript., AA, SS, AH, SOS, AF performed data collection, data entry and drafted the manuscript, RA reviewed the manuscript All authors read and approved the final manuscript.

\section{Acknowledgements}

We would like to thank the study participants and the administrative department in Ibn Sina Hospital for actively participating in the study. Gratitude to Ministry of Education in Kuwait for their support to the study.

\section{Conflicts of Interest}

All authors declare that there are no conflicts of interest.

\section{Data Availability}

Source documents are available on request from the Department of Neurology, at administrative section, Ibn Sina Hospital, Safat, Kuwait. P.O.Box 25427, 13115 Safat, Kuwait City, Kuwait.

\section{References}

1. Bille B. Migraine and tension-type headache in children and adolescents. 1996; 80-80

2. Keight R et al (2017) Towards the discrimination of primary and secondary headache: An intelligent systems approach. International Joint Conference on Neural Networks (IJCNN). IEEE; 2017

3. Fearon P, Hotopf M (2001) Relation between headache in childhood and physical and psychiatric symptoms in adulthood: national birth cohort study. Bmj 322:7295 1145.

4. Passchier J, Orlebeke JF (1985 Sep) Headaches and stress in schoolchildren: an epidemiological study. Cephalalgia 5(3):167-176

5. Pop PH, Gierveld CM, Karis HA, Tiedink HG (2002 Mar) Epidemiological aspects of headache in a workplace setting and the impact on the economic loss. European journal of neurology 9(2):171-174

6. Stovner LJ, Hagen K, Jensen R, Katsarava Z, Lipton RB, Scher Al, Steiner TJ, Zwart JA. The global burden of headache: a documentation of headache prevalence and disability worldwide. Cephalalgia. 2007 Mar;27(3):193-210

7. Nodari E, Battistella PA, Naccarella C, Vidi M (2002 Apr) Quality of life in young Italian patients with primary headache. Headache: The Journal of Head Face Pain 42(4):268-274

8. Arruda MA, Bigal ME (2012 Nov) Behavioral and emotional symptoms and primary headaches in children: a population-based study. Cephalalgia 32(15):1093-1100

9. Galli F, D'Antuono G, Tarantino S, Viviano F, Borrelli O, Chirumbolo A, Cucchiara S, Guidetti V (2007) Headache and recurrent abdominal pain: a controlled study by the means of the Child Behaviour Checklist (CBCL). Cephalalgia. Mar;27(3):211-9

10. Bruijn J, Locher H, Passchier J, Dijkstra N, Arts WF. Psychopathology in children and adolescents with migraine in clinical studies: a systematic review. Pediatrics. 2010 Aug 1;126(2):323 - 32

11. Virtanen R, Aromaa M, Koskenvuo M, Sillanpää M, Pulkkinen L, Metsähonkala L, Suominen S, Rose RJ, Helenius H, Kaprio J (2004) Externalizing problem behaviors and headache: a follow-up study of adolescent Finnish twins. Pediatrics. Oct 1;114(4):981-7

12. Clarke CE, MacMillan L, Sondhi S, Wells NE (1996 Jan) Economic and social impact of migraine. QJM: monthly journal of the Association of Physicians 89(1)(1):77-84

13. Al-Hashel JY, Ahmed SF, Alroughani R. Prevalence and Burden of Primary Headache Disorders in Kuwaiti Children and Adolescents: A Community Based Study. Frontiers in neurology. 2019;10

14. Wöber-Bingöl Çiçek (2013) Epidemiology of migraine and headache in children and adolescents. Curr Pain Headache Rep 17:341 6 )

15. Wöber-Bingöl Ç, Wöber C, Uluduz D, Uygunoğlu U, Aslan TS, Kernmayer M, Zesch HE, Gerges NT, Wagner G, Siva A, Steiner TJ (2014 Dec) The global burden of headache in children and adolescents-developing a questionnaire and methodology for a global study. The journal of headache 
pain 15(1):86

16. Steiner TJ, Gururaj G, Andrée C, Katsarava Z, Ayzenberg I, Yu SY, Al Jumah M, Tekle-Haimanot R, Birbeck GL, Herekar A, Linde M (2014) Diagnosis, prevalence estimation and burden measurement in population surveys of headache: presenting the HARDSHIP questionnaire. The journal of headache and pain. Dec 1;15(1):3

17. Headache Classification Committee of the International Headache Society (IHS) The International Classification of Headache Disorders, 3rd edition (2018) Cephalalgia, 38(1), 1-211. https://doi.org/10.1177/0333102417738202

18. Foster CG (1994 Jun) International ethical guidelines for biomedical research involving human subjects. Journal of medical ethics $20(2): 123$

19. World Medical Association. "Declaration of Helsinki. Ethical principles for medical research involving human subjects." http://www. wma. net/e/policy/b3. htm 2008

20. Işik U, Topuzoğlu A, Ay P, Ersu RH, Arman AR, Onsüz MF, Karavuş M, Dağli E (2009 May) The prevalence of headache and its association with socioeconomic status among schoolchildren in istanbul, Turkey. Headache 49(5):697-703

21. Rho Yl, Chung HJ, Lee KH, Eun BL, Eun SH, Nam SO, Kim WS, Kim YO, Park HJ, Kim HS (2012 Apr) Prevalence and clinical characteristics of primary headaches among school children in South Korea: a nationwide survey. Headache: The Journal of Head Face Pain 52(4):592-599

22. Philipp J, Zeiler M, Wöber C, Wagner G, Karwautz AF, Steiner TJ, Wöber-Bingöl Ç (2019) Prevalence and burden of headache in children and adolescents in Austria-a nationwide study in a representative sample of pupils aged 10-18 years. The journal of headache and pain. Dec 1;20(1):101

23. Passchier J, Orlebeke JF (1985 Sep) Headaches and stress in schoolchildren: an epidemiological study. Cephalalgia 5(3):167-176

24. Kröner-Herwig B, Heinrich M, Morris L (2007 Jun) Headache in German children and adolescents: a population-based epidemiological study. Cephalalgia 27(6):519-527

25. Laurell K, Larsson B, Eeg-Olofsson O (2004 May) Prevalence of headache in Swedish schoolchildren, with a focus on tension-type headache. Cephalalgia 24(5):380-388

26. Lateef TM, Merikangas KR, He J, Kalaydjian A, Khoromi S, Knight E, Nelson KB (2009 May) Headache in a national sample of American children: prevalence and comorbidity. J Child Neurol 24(5):536-543

27. Ozge A, Sasmaz T, Cakmak SE, Kaleagasi H, Siva A (2010 Jun) Epidemiological-based childhood headache natural history study: after an interval of six years. Cephalalgia 30(6):703-712

28. Dooley JM, Gordon KE, Wood EP (2005 Feb) Self-reported headache frequency in Canadian adolescents: Validation and follow-up. Headache: The Journal of Head Face Pain 45(2):127-131

29. Gaßmann J, Vath N, van Gessel H, Kröner-Herwig B (2009 Jul) Risk factors for headache in children. Deutsches Ärzteblatt International 106:3132):509

30. Fendrich K, Vennemann M, Pfaffenrath V, Evers S, May A, Berger K, Hoffmann W (2007 Apr) Headache prevalence among adolescents-the German DMKG headache study. Cephalalgia 27(4):347-354

31. Santinello M, Vieno A, De Vogli R (2009 Mar) Primary headache in Italian early adolescents: the role of perceived teacher unfairness. Headache: The Journal of Head Face Pain 49(3):366-374

32. Mehta S (2015 Jan) Study of various social and demographic variables associated with primary headache disorders in 500 school-going children of central India. Journal of pediatric neurosciences 10(1):13

33. Wöber C, Wöber-Bingöl Ç, Uluduz D, Aslan TS, Uygunoglu U, Tüfekçi A, Alp SI, Duman T, Sürgün F, Emir GK, Demir CF (2018) Undifferentiated headache: broadening the approach to headache in children and adolescents, with supporting evidence from a nationwide school-based crosssectional survey in Turkey. The journal of headache and pain. Dec 1;19(1):18

34. Zwart JA, Dyb G, Holmen TL, Stovner LJ, Sand T (2004 May) The prevalence of migraine and tension-type headaches among adolescents in Norway. The Nord-Trøndelag Health Study (Head-HUNT-Youth), a large population-based epidemiological study. Cephalalgia 24(5):373-379

35. Lyngberg AC, Rasmussen BK, Jørgensen T, Jensen R. Incidence of primary headache: a Danish epidemiologic follow-up study. American journal of epidemiology. 2005 Jun 1;161(11):1066-73

36. Allais G, Chiarle G, Sinigaglia S, Benedetto C. Menstrual migraine: a review of current and developing pharmacotherapies for women. Expert opinion on pharmacotherapy. 2018 Jan 22;19(2):123 - 36

37. Vincent K, Tracey I (2010) Sex hormones and pain: the evidence from functional imaging. Current pain and headache reports. Oct 1;14(5):396403

\section{Figures}




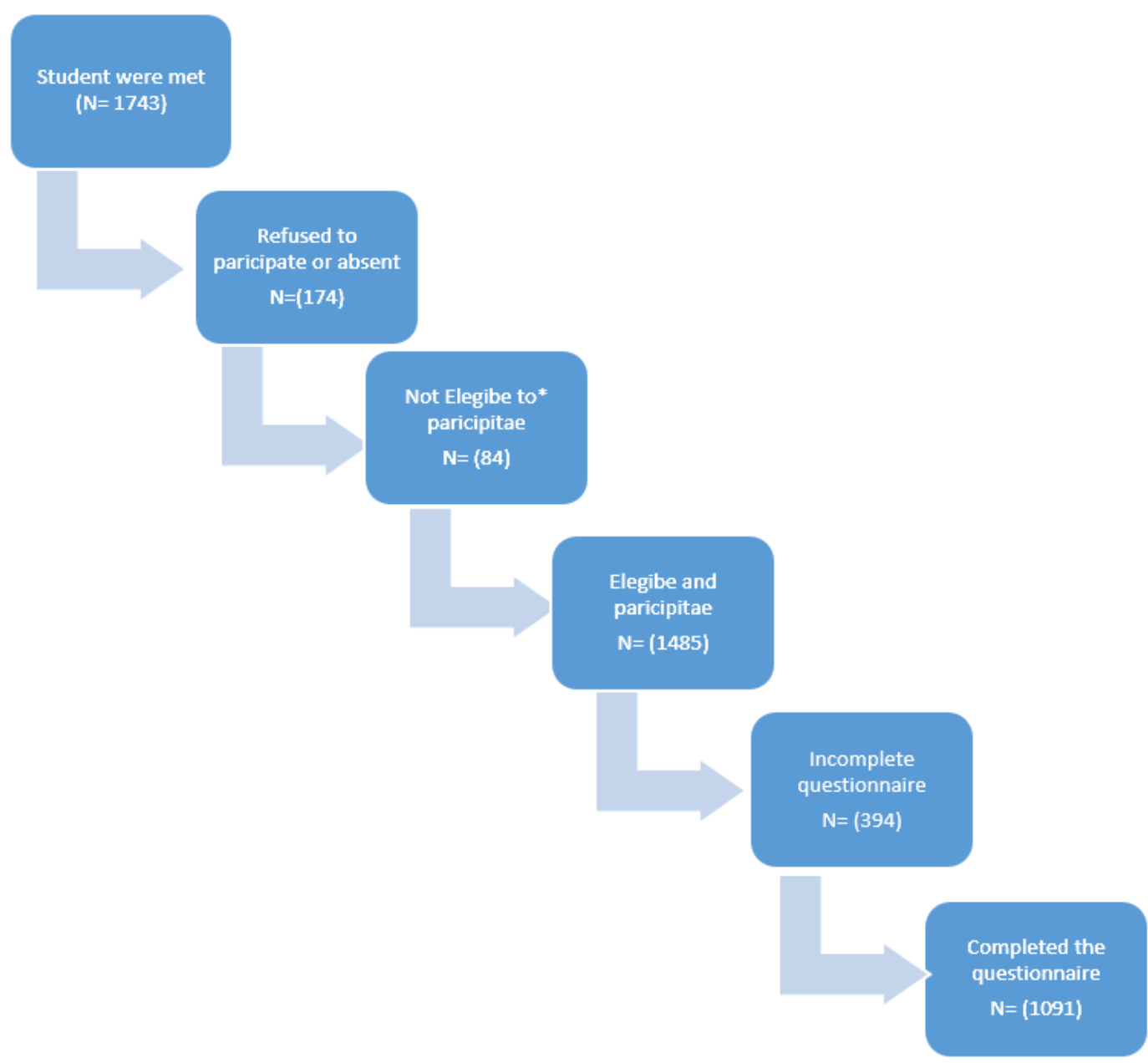

\section{Figure 1}

Flow chart of participants. *Non Kuwaiti, has medical or neurological disorder, or younger than 7 years. 